\title{
Oral Angioleiomyoma in Early Childhood Patient: A Case Report of an Uncommon Lesion and Literature Review
}

\author{
Thâmara MM Bezerra ${ }^{1}$, Filipe N Chaves ${ }^{2}$, Francisco SR Carvalho ${ }^{3}$, Fábio WG Costa ${ }^{4}$, Ana PNN Alves ${ }^{5}$, Mário RL Mota ${ }^{6}$, \\ Karuza MA Pereira ${ }^{7}$
}

\begin{abstract}
Leiomyoma is a benign soft tissue tumor originating from smooth muscle, rarely seen in the oral cavity, due to the scarcity of this tissue in the mouth. The tumor may occur at any age, without sex predilection. Rare reports of this lesion have been in pediatric patients. The lesion is typically asymptomatic and has slow growth, the final diagnosis is defined by histopathological and immunohistochemical examination. Treatment involves resection of the lesion. The lesion is classified histologically as solid leiomyomas, angioleiomyomas (AL), or epithelioid leiomyomas. We report the case of a 1-year-old female child with a painless papule on the hard palate. Histopathological examination revealed biphasic LA showing proliferation of spindle-shaped nuclear cells in straw-shaped bundles or a concentric design. This is the fourth documented case of AL in early childhood.

Keywords: Angioleiomyoma, Early childhood, Palate, Pediatric patient, Smooth muscle tumor. International Journal of Clinical Pediatric Dentistry (2021): 10.5005/jp-journals-10005-2082
\end{abstract}

\section{BACKGROUND}

Leiomyoma is benign smooth muscle tumor that is more frequent in the uterus and gastrointestinal system.,2 They can be divided into three subtypes on the basis of their cytoarchitecture: solid leiomyoma (leiomyoma), angioleiomyoma $(\mathrm{AL})$, and epithelioid leiomyoma (leiomyoblastoma). ${ }^{3,4}$ ALs, also known as vascular leiomyomas, angiomyomas, or dermal angiomas (in the skin) ${ }^{5}$ have been observed in the subcutaneous tissue of the lower extremities, ${ }^{6}$ and are very rare in the oral cavity. ${ }^{1,4,6-10}$ In a research with oral cavity and pharynx leiomyoma and leiomyosarcoma data from 1884 until 1996 detected only 139 leiomyomas cases and the most common histological variant was AL. ${ }^{11}$ The mean age is 45 years, with a slight predilection for males, and it is rare in children. ${ }^{1,4,11-14}$ We experienced an AL case in a 1-year-old child's palate and it is presented with a literature review (LR) discussing clinical findings, the modern pathological knowledge, and the management of the lesion.

\section{Case Description}

A 12-month-old female was referred to the Clinic of Stomatology of the Federal University of Ceará-Campus Sobral to evaluate a palate swelling, which caused discomfort and sporadic bleeding. The intraoral inspection revealed pedunculated papule, measuring approximately $0.6 \times 0.4 \times 0.2 \mathrm{~cm}$, located on the hard palate, in the region of incisive papilla, covered by healthy mucosa with ulcerated area, smooth surface, and soft texture (Fig. 1). No teeth mobility was detected. The legal responsible reported that the lesion was noted when the child was 9-month-old and it has not grown in the meantime. There was no infection, trauma, or pain history, but the child had non-nutritive sucking habits. The parents did not report genetic or other medical conditions. We performed a periapical radiography of the region, which did not reveal any dental or bone alterations, as the lesion was restricted to soft tissue. The clinical hypothesis was pyogenic granuloma or traumatic fibroma, and an excisional biopsy was done. The specimen was examined
${ }^{1}$ Dental Clinic Department, Postgraduate Program in Dentistry, Federal University of Ceará, Fortaleza, Ceará, Brazil

${ }^{2,3} \mathrm{~S}$ chool of Dentistry, Postgraduate Program in Health Sciences, Federal University of Ceará, Sobral, Ceará, Brazil

${ }^{4}$ Division of Oral and Maxillofacial Surgery, Postgraduate Program in Dentistry, Federal University of Ceará, Fortaleza, Ceará, Brazil

${ }^{5,6}$ Division of Oral Pathology, Postgraduate Program in Dentistry, Federal University of Ceará, Fortaleza, Ceará, Brazil

${ }^{7}$ Department of Morphology, Postgraduate Program in Dentistry, Federal University of Ceará, Fortaleza, Ceará, Brazil

Corresponding Author: Filipe N Chaves. Rua Conselheiro José Júlio, S/N , Centro, Sobral, Ceará - CEP: 62.010-820. Phone/Fax: (55) (88) 36954622, e-mail: filipenobrechaves@gmail.com

How to cite this article: Bezerra TMM, Chaves FN, Carvalho FSR, et al. Oral Angioleiomyoma in Early Childhood Patient: A Case Report of an Uncommon Lesion and Literature Review. Int J Clin Pediatr Dent 2021;14(6):828-832.

Source of support: Nil

Conflict of interest: None

at the Oral Pathology Laboratory of the Federal University of Ceará. The microscopic exam showed well-circumscribed and unencapsulated mass composed of smooth muscle cells arranged in divergent fascicles around many vascular channels (Figs 2A and B). Interestingly, the tumor exhibits a biphasic pattern with capillary vascular proliferation on the specimen center, with a solid appearance in this region, and venous proliferation on the peripheral portion (Figs 2A and B). The fascicles sometimes showed spiral formation (Fig. 2C). The smooth muscle cells have a low pleomorphism degree, elongated oval nuclei, and eosinophilic cytoplasm ("cigar shaped" nuclei) (Fig. 2D). The staining technique was Masson's Trichrome, which stained the collagen fibers blue and the smooth muscle cells red (Fig. 2E). Based on these findings, the final diagnosis was AL. Immunohistochemical reactions were performed to illustrate the case. The positivity for a-SMA

() The Author(s). 2021 Open Access This article is distributed under the terms of the Creative Commons Attribution 4.0 International License (https://creativecommons. org/licenses/by-nc/4.0/), which permits unrestricted use, distribution, and non-commercial reproduction in any medium, provided you give appropriate credit to the original author(s) and the source, provide a link to the Creative Commons license, and indicate if changes were made. The Creative Commons Public Domain Dedication waiver (http://creativecommons.org/publicdomain/zero/1.0/) applies to the data made available in this article, unless otherwise stated. 


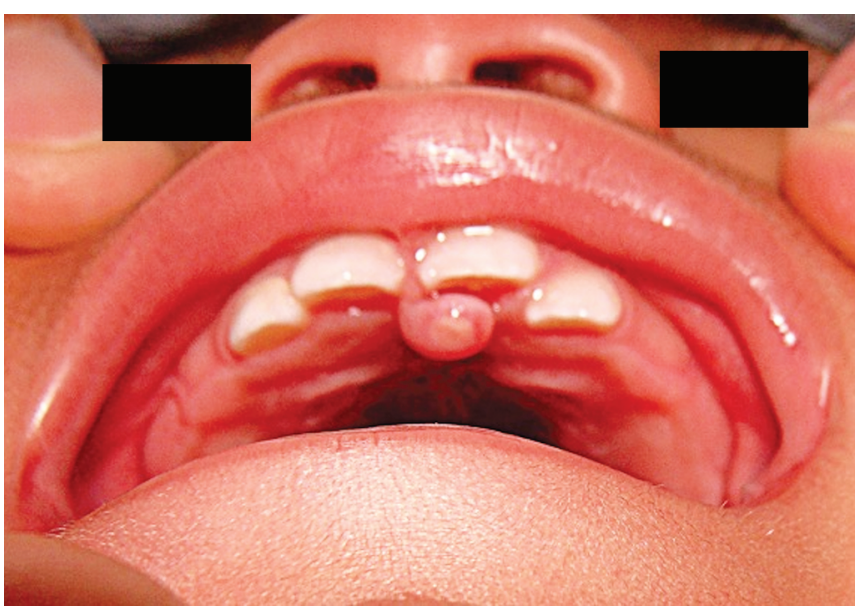

Fig. 1: Preoperative image reveals a normochromic nodule located in the region of incisive papilla

(Alpha-Smooth Muscle Actin) showed that the lesion had muscle origins (Fig. 2F) and through CD34, it was possible to observe the vascular component (Fig. 2G). The patient is on follow-up and disease-free for 2 years.

\section{Discussion}

Leiomyoma is a benign neoplasm with vascular smooth muscle (tunica media) origin. 1,14 It is observed in sites abundant with smooth muscles such as the myometrium, the gastrointestinal tract, and the skin. ${ }^{15}$ Leiomyoma is relatively rare or uncommon in oral cavity due to smooth muscle scarceness in this location. ${ }^{13,15}$ The origins of smooth muscle in the oral cavity are circumvallate papillae, blood vessels, heterotopic smooth muscle, and remains of embryonic tissue. ${ }^{3,15} \mathrm{An}$ interesting theory is that the pericyte is responsible for the AL development. ${ }^{4}$ These pericytes can be considered as progenitors for vascular smooth muscle cells in AL. ${ }^{4}$ The proliferation of pericytes may occur due to infection, trauma, hormones (especially estrogen), venous stasis, and arteriovenous malformations. ${ }^{10,14}$ In this case, the practice of non-nutritive sucking may have led to mild, but constant, trauma in the region, which makes us suppose that this is the most likely hypothesis for the appearance of the injury. The articles on early childhood ALs contained in our LR do not offer any hypotheses for the appearance of this pathology in children.

A current investigation involving tumorigenesis proposes that its development is associated with genetic features. ${ }^{15}$ Reports suggest that approximately half of leiomyomas contain nonrandom abnormalities in chromosomes and only a subset is tumor specific. One of the most common translocations is $\mathrm{t}(12 ; 14)(\mathrm{q} 15 ; \mathrm{q} 24)$ which occur in approximately one-fifth of karyotypes. Other aberrations include 6 p21 rearrangements, del(7)(q22-q32), and trisomy 12. Additional abnormalities include structural rearrangements of chromosome 3 , monosomy 22 , del(10q), and monosomy $10 .{ }^{15}$ Different subgroups of this neoplasm may show chromosomal patterns which reflect site specificity or cytogenetic heterogeneity. In the oral cavity, we found only one study of cytogenetic reports, which revealed normal karyotype in an AL located on the buccal vestibule of a 39-year-old man. ${ }^{16}$ The reason for normal karyotype might occur due to difference in the tumor histological grade at the moment of the analysis, or to a site-specific etiology. ${ }^{16}$
$A L$ is rarely found during infancy and adolescence and this is the fourth reported AL case in early childhood. ${ }^{15}$ Oral cavity ALs are more common in males and usually present themselves in lips (more frequently on the lower lip), and buccal mucosa of the cheek and palate. ${ }^{4,7,13,16}$ Even including the present report in our bibliographic survey, the small number of cases does not allow us to trace an epidemiological profile of ALs in children. However, all cases from this LR were males, similar to adult ALs.

The AL clinical appearance is unspecific, which makes the differential diagnosis more difficult. ${ }^{1,5,7}$ Although ALs are histologically regarded as vascular lesions, their clinical appearance is not similar to these types of lesions. ${ }^{13}$ Tumors with benign mesenchymal origin (lipoma, fibroma, neurofibroma, and schwannoma), benign lesions of salivary gland origin (pleomorphic adenoma and nonbullous mucocele), vascular lesions (lymphangioma and hemangioma), reactive lesions (pyogenic granuloma), soft tissue cysts (dermoid cyst) as well as malign pathologies (adenoid cystic carcinoma, mucoepidermoid carcinoma, and non-Hodgkin's lymphoma) must be included as possible diagnosis for this lesion. ${ }^{6,7}$ In children, the LR showed that the clinical diagnosis is similar to the adults', since the same lesion types are also considered (Table 1). In this case, clinical suspicion of pyogenic granuloma was considered because the lesion was bleeding and the patient did not have satisfactory oral hygiene and presented plaques on the superior incisive teeth.

Among three different types/major groups of leiomyomas, the vascular form is the most common., ${ }^{413}$ The AL diagnosis is mainly histological, which is why there are no report of this lesion as main clinical hypothesis. The World Health Organization (WHO) categorized it into three histological subtypes: solid, venous, and cavernous. ${ }^{3}$ The solid subtype has small vascular channels and bundles of compacted smooth muscle. The venous-type tumors have larger channels with thicker walls of muscle. Tumors with the cavernous subtype consist of enlarged blood vessels and the walls are hard to discern from the muscular fiber bundles. It is possible to have a blend of patterns leading to biphasic lesions. ${ }^{8}$ For some researchers, AL represents just one stage in the pathological smooth muscle proliferation process. ${ }^{16}$ The potential progression would be hemangioma, angioma, angiomyoma, leiomyoma, and solid leiomyoma. ${ }^{16}$ This theory may justify the presence of biphasic tumors, as this case, which presents a more solid component in its central portion and venous in its periphery, suggesting a maturation process. Interestingly, in the early childhood, we found that all the cases contained in our LR, as well as the present case report, were of the AL subtype. This may also support the theory that it is just one stage in the pathological smooth muscle proliferation process, ${ }^{16}$ since the biopsy is performed during early childhood with no time for the pathological process to progress. However, an epidemiological study involving different age groups and lesion evolution time is necessary to confirm this theory. The histology may show marked degenerative changes with hyalinization, myxoid changes, and calcification. ${ }^{14}$ However, this case did not present any of these findings.

The differential diagnosis should consider other spindleshaped cells benign lesions that may resemble $A L$, such as hemangiopericytoma, hemangioendothelioma, neurilemmoma, myofibroma, neurofibroma, nodular fasciitis, and hamartomatous lesions with smooth muscle, such as vascular and neurovascular hamartomas. ${ }^{2,6,7}$ 

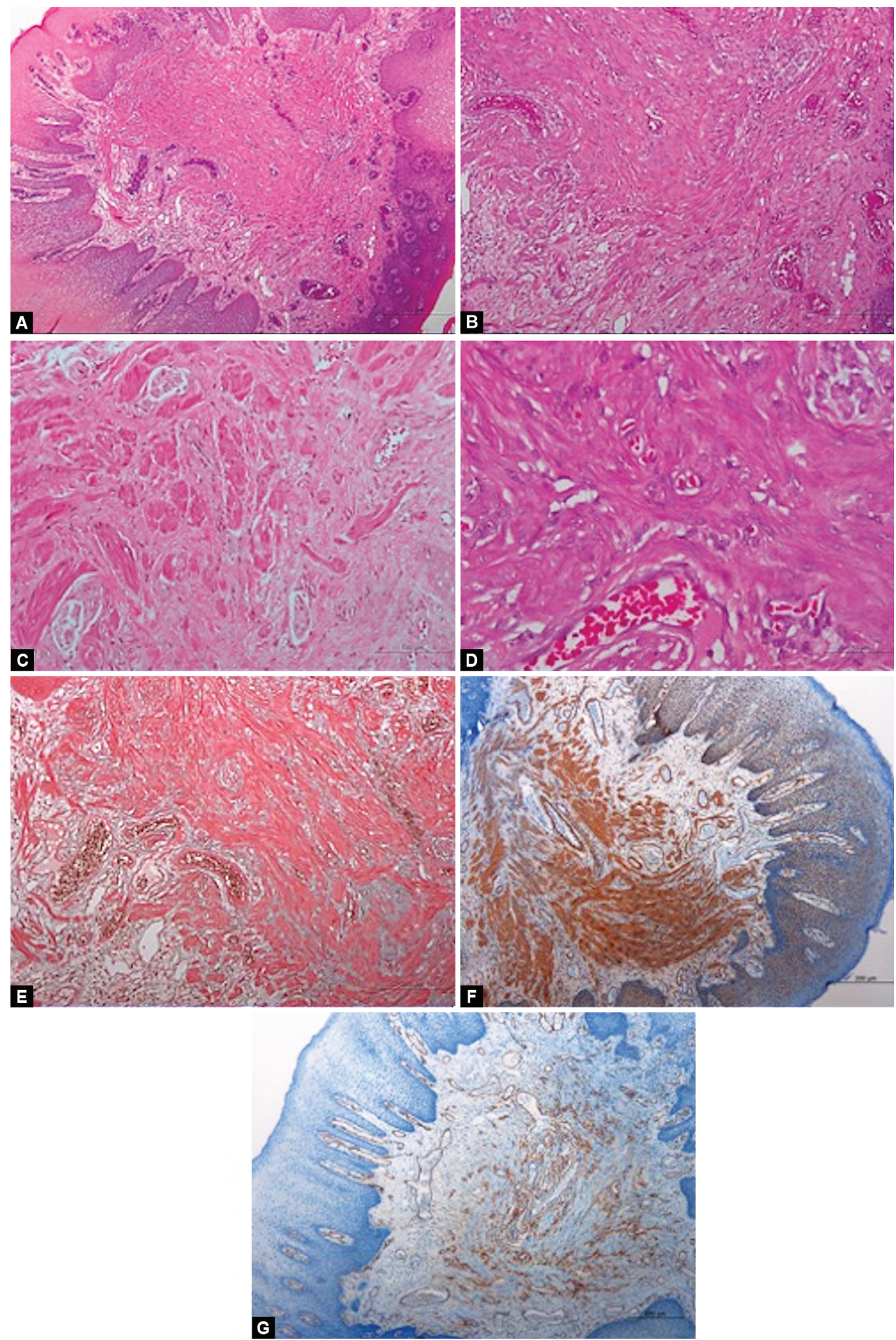

Figs 2A to G: (A) Photomicrography shows a unencapsulated mass composed of many dilated vascular channels (HE 100x); (B) Smooth muscle proliferation around the vessels (HE 100x). The specimen has a biphasic pattern with the central part more solid, with some capillary diameter vascular channels, while its periphery has more venous characteristics; (C) Fusiform cells arranged in spirals around small vascular spaces (HE 200x); (D) Fascicles of pale spindle cells with eosinophilic cytoplasm and elongated oval nuclei (HE 400x); (E) Staining of smooth muscle cells is red and the collagen fibers are blue (Masson's Trichrome 200x); (F) Intense marking for a-SMA in the cytoplasm of neoplastic cells (Streptoavidin-biotin 200x); (G) Blood vessels of different calibers, immunopositive for CD34 (Streptoavidin-biotin 200x). 
Table 1: Oral angioleiomyoma in pediatric patients reported in literature

\begin{tabular}{|c|c|c|c|c|c|c|c|c|}
\hline Author(s)/year & $\begin{array}{l}\text { No. } \\
\text { of } \\
\text { cases }\end{array}$ & $\begin{array}{l}\text { Histopathological } \\
\text { subtype }\end{array}$ & Gender & $\begin{array}{l}\text { Age } \\
\text { (in years) }\end{array}$ & Location & $\begin{array}{l}\text { Clinical diagnosis } \\
\text { (before biopsy) }\end{array}$ & Immunohistochemistry & Histochemical stain \\
\hline $\begin{array}{l}\text { Reddy BVR, } \\
\text { Shoba Rani } \\
\text { B, Anuradha } \\
\text { CH, Chan- } \\
\text { drasekhar P, } \\
\text { Shamala R, } \\
\text { Lingamaneni } \\
\text { KP }(2011)^{(2)}\end{array}$ & 1 & $A L$ & Male & 9 & $\begin{array}{l}\text { Mandible } \\
\text { (right side of } \\
\text { the body) }\end{array}$ & $\begin{array}{l}\text { Ossifying fibroma, } \\
\text { central giant cell } \\
\text { granuloma, neurofi- } \\
\text { broma, neurilem- } \\
\text { moma, myofibroma } \\
\text { of the mandible } \\
\text { and osteoma }\end{array}$ & $\begin{array}{l}\text { a-SMA (+); } \\
\text { Vimentin (+); } \\
\text { S-100 (-); and } \\
\text { Desmin (-) }\end{array}$ & - \\
\hline $\begin{array}{l}\text { Kim YH, } \\
\text { Jang YW, Pai } \\
\text { H, Kim SG } \\
(2010)^{(5)}\end{array}$ & 1 & $A L$ & - & $\begin{array}{l}0,17 \text { or } \\
\text { 2-mouth- } \\
\text { old-infant }\end{array}$ & $\begin{array}{l}\text { Tongue } \\
\text { (posterior) }\end{array}$ & - & $\begin{array}{l}\operatorname{Desmin}(+) ; \\
\text { a-SMA (+); } \\
\text { Vimentin (-); and } \\
\text { S-100 (-) }\end{array}$ & Masson trichrome \\
\hline $\begin{array}{l}\text { Toida M, } \\
\text { Koizumi H, } \\
\text { Shimokawa K } \\
(2000)^{(11)}\end{array}$ & 1 & $\begin{array}{l}\text { AL solid type } \\
\text { with a partially } \\
\text { venous pattern }\end{array}$ & Male & 10 & Lower lip & $\begin{array}{l}\text { Mucocele or } \\
\text { mesenchymal } \\
\text { tumor associated } \\
\text { with infection }\end{array}$ & $\begin{array}{l}\text { a-SMA }(+) \\
\text { S-100 (-) }\end{array}$ & $\begin{array}{l}\text { Masson trichrome } \\
\text { and Van Giesson }\end{array}$ \\
\hline
\end{tabular}

a-SMA, alpha-smooth muscle actin; (-), without information; (+), in the presence of primary antibody

The histopathological criteria used to predict malignancy, such as cell size and shape increased irregularity, increased cell size, incomplete cell differentiation, presence of short, plump cells with oval nuclei and presence of cells with hyperchromic and multiple nuclei with inconstant staining are used to differentiate AL from its malignant counterpart (angioleiomyosarcoma). However, the presence of pleomorphism, cellular atypia, and necrosis is common in $\mathrm{AL}$ and angioleiomyosarcoma. ${ }^{15}$ The mitotic figures are rarely seen in $\mathrm{AL}^{1}$, ergo the number of mitosis is the main gauge to determine malignancy. ${ }^{2,14}$ Although this quantity is not well established, ${ }^{10}$ researchers agree that if there are $<2$ mitoses per 10 high power fields (HPFs), the prognosis is good and cases that $\geq 2$ mitotic figures per $10 \mathrm{HPFs}$ are deemed malignant. ${ }^{11}$ Since the malignant pattern may be on a small portion of the tumor, it is important that the entire specimen is subjected to histopathological analysis. In this case, the entire specimen was examined and, through the histopathological exam, no evidence of malignancy was detected.

Immunohistochemical analysis is important in the diagnosis of AL. The most frequent markers assessed are CD34, a-SMA, desmin, vimentin, and S-100. ${ }^{14}$ The immunohistochemical markers most used for the AL diagnosis, according to our LR, were a-SMA (positive for all cases) and S-100 (positive only in small nerve fibers). Desmin did not show the same staining profiles in the studies, since its immunostaining was different among them (Table 1). However, despite desmin is an intermediate filament subunit in all muscle tissues, and is one of the earliest protein markers on them, HHF-35 (smooth muscle marker) is more specific for AL. ${ }^{8}$ Special stains specific for smooth muscle actin are useful in distinguishing smooth muscle from collagen. ${ }^{10}$ Thus, Masson trichrome, Phosphotungstic Acid Haematoxylin (PTAH), and Mallory's phosphotungstic acid are routine histochemical steins able to identify the smooth muscle, turning them into useful, easy to access, and low-cost tools to diagnose ALs. Our LR showed that only one study did not use histochemical stains to help achieve the histopathological diagnosis (Table 1). We used Masson trichrome in this current case (Fig. 2E), which revealed red-stained smooth muscle cell cytoplasm, and blue-stained collagenous fibrous tissue, contributing to the final histologic diagnosis of AL. The immunohistochemical exam was used only to illustrate the case, since there was no histopathologic controversy. Although each immunohistochemical marker is tissue-specific, they become useful only when combined with the clinical findings and the measurement of other markers.

The surgical excision is the oral AL main treatment. ${ }^{5,7,8,11,13}$ In this case, an excisional biopsy was performed, because of the tumor's small size and absence of signs of malignancy. This lesion seldomly recurs and this frequently comes from an inadequate security margin..$^{1,8,13}$ The patient should be accompanied for at least a year postsurgery. ${ }^{1,7,8}$ The patient of this case is on periodical evaluations.

\section{Conclusion}

In summary, oral leiomyoma is rare due to paucity of the smooth muscles. In pediatric patients, AL is the most prevalent histological subtype and should be considered in the clinical differential diagnosis due to its wide age range of occurrence. Although the malignancy rate has not been reported in the literature, a careful periodic evaluation should be planned.

\section{Clinical Significance}

We did an English-language LR to identify the clinical hypotheses, the most prevalent histological pattern as well as which tools may help the AL histopathological diagnosis in the oral cavity of children. The keywords "angioleiomyoma," "angiomyoma," "vascular leiomyomas," "solid leiomyoma," "leiomyoma," "epithelioid leiomyoma," "leiomyoblastoma," and "case report" were researched on PubMed. We considered the articles published until April 2020 and 1,147 results were identified. Cases in nonoral sites or that did not affect children were excluded. Thus, we selected three studies, with a total of three ALs cases (Table 1). 


\section{References}

1. Eley KA, Alroyayamina S, Golding SJ, et al. Angioleiomyoma of the hard palate: report of a case and review of the literature and magnetic resonance imaging findings of this rare entity. Oral Surg Oral Med Oral Pathol Oral Radiol 2012 Aug;114(2):e45-e49. DOI: 10.1016/j. oooo.2012.01.014

2. Reddy BVR, Shoba Rani B, Anuradha $\mathrm{CH}$, et al. Leiomyoma of the mandible in a child. J Oral Maxillofac Pathol 2011;15:101-104. DOI: 10.4103/0973-029X.80015

3. Radhakrishna M, Varghese S, Sreenivasan B, et al. Angiomyoma of the hard palate - report of a rare case. Int Arab J Dent 2015;6:37-39. Retrieved from https://journals.usj.edu.lb/iajd/article/view/200

4. World Health Organization. Pathology and genetics of tumors of soft tissue and bone. Lyon: IARC 2002.

5. Kim YH,Jang YW,PaiH, etal.Congenitalangiomyoma of thetongue:case report. Dentomaxillofac Radiol 2010 Oct;39(7):446-448. DOI: 10.1259/ dmfr/32524441

6. Mahima VG, Patil K, Srikanth HS. Recurrent oral angioleiomyoma. Contemp Clin Dent 2011;2(2):102-105. DOI: 10.4103/0976237X.83071

7. Tatehara S, Sato T, Mishima K, et al. Angioleiomyoma of the hard palate: Report of a case and review of literature. J Oral Maxillofac Surg Med Pathol 2013;25(3):282-286. DOI: 10.1016/j.ajoms.2012.05.002

8. Pandya M, Rao DS, Mamatha GP, et al. Angiomyoma - a requisite in differential diagnosis of palatal growths. Int J Health Sci (Qassim) 2019;13(6):47-49 PMID: 31745398.
9. Hung KF, Yan AH, Kao SY, et al. Angioleiomyoma in right lingual gingiva- a case report. Chin J Oral Maxillofac Surg 2005;16:179-187. DOI: 10.7104/CJOMS.200509.0179

10. Wertheimer-Hatch L, Hatch III GF, Hatch KF, et al. Tumors of the oral cavity and pharynx. World J Surg 2000;24(4):395-400. DOI: 10.1007/ s002689910064

11. Toida M, Koizumi H, Shimokawa K. Painful angiomyoma of the oral cavity: report of a case and review of the literature. J Oral Maxillofac Surg 2000;58(4):450-453. DOI: 10.1016/s0278-2391(00)90935-2

12. Brooks JK, Nikitakis NG, Goodman NJ, et al. Clinicopathologic characterization of oral angioleimyomas. Oral Surg Oral Med Oral Pathol Oral Radiol Endod 2002;94(2):221-227. DOI: 10.1067/ moe.2002.125276

13. Ramesh P, Annapureddy SR, Khan F, et al. Angioleiomyoma: a clinical, pathological and radiological review. Int J Clin Pract 2004;58(6):587591.DOI: 10.1111/j.1368-5031.2004.00085.x

14. Giudice A, Bennardo F, Buffone $C$, et al. Clinical and immunohistochemical features of oral angioleiomyoma: a comprehensive review of the literature and report of a case in a young patient. Case Rep Dent2019;2498353. DOI: 10.1155/2019/2498353

15. Chang L, Rao N, Bernthal N, et al. An unusual karyotype in leiomyoma: case report and literature review. J Orthop 2015;12(Suppl 2):S251S254. DOI: 10.1016/j.jor.2015.10.016

16. Manor E, Sion-Vardy N, Nash M, et al. Angiomyoma of buccal vestibule: a rare case with a normal karyotype. J Laryngol Otol 2007;121(12):1210-1212. DOI: 10.1017/S0022215107008808 